\title{
Improvement of Inflammation through Antioxidant Pathway of Gardeniae Fructus 50\% EtOH Extract (GE) from Acute Reflux Esophagitis Rats
}

\author{
Soo Hyun Kim $\mathbb{D}^{1},{ }^{1}$ Mi-Rae Shin $\left(\mathbb{D},{ }^{1}\right.$ Ah Reum Lee, ${ }^{2}$ Bu-Il Seo, ${ }^{1}$ Hae-Jin Park, ${ }^{3}$ \\ and Seong-Soo Roh $\mathbb{1}^{1}$ \\ ${ }^{1}$ Department of Herbology, College of Korean Medicine, Daegu Haany University, 136, Shinchendong-ro, Suseong-gu, \\ Deagu 42158, Republic of Korea \\ ${ }^{2}$ Department of Beauty Design, Hosan University, Gyeongsan, Republic of Korea \\ ${ }^{3}$ Faculty of Herbal Cuisine and Nutrition, Daegu Haany University, Gyeongsan, Republic of Korea
}

Correspondence should be addressed to Seong-Soo Roh; ddede@dhu.ac.kr

Received 6 November 2019; Revised 19 January 2020; Accepted 21 January 2020; Published 25 February 2020

Academic Editor: Jane Hanrahan

Copyright ( $(2020$ Soo Hyun Kim et al. This is an open access article distributed under the Creative Commons Attribution License, which permits unrestricted use, distribution, and reproduction in any medium, provided the original work is properly cited.

Gardeniae Fructus 50\% EtOH extract (GE) is a traditional herb that has been used to treat a variety of diseases. In this study, we investigate the antioxidant, anti-inflammatory, and antiapoptotic properties of GE on acute reflux-induced esophagitis (RE) model in rats. 2,2'-Azino-bis (3-ethylbenzothiazolin-6-sulfonic acid) (ABTS) and 2,2-diphenyl-1-picrylhydrazyl (DPPH) radical scavenging assays were performed to determine the antioxidant activity of GE. GE was given orally at 50 and $100 \mathrm{mg} / \mathrm{kg}$ body weight $1 \mathrm{~h} 30 \mathrm{~min}$ prior to RE induction. And its effect was assessed in comparison with RE control and normal groups. The administration of the extract of the GE showed remarkable protection of mucosal damage in esophageal tissue, and the histologic observation showed that the gastric lesion was improved. Increased reactive oxygen species (ROS) levels in the serum were diminished by GE treatment. The antioxidative biomarkers including nuclear factor-erythroid 2-related factor 2 (Nrf-2), heme oxygenase-1 (HO-1), superoxide dismutase (SOD), catalase, and glutathione peroxidase (GPX) were significantly increased. GE administration significantly reduced the inflammatory protein expression through MAPK-related signaling pathways and the nuclear factor-kappa B (NF- $\kappa$ B) pathway. These results suggest that GE protects the esophagus mucosal membrane by attenuating oxidative stress and inflammatory response under reflux esophagitis condition through the antioxidant pathway. Therefore, it is suggested that GE may be a potential remedy for the treatment of reflux esophagitis.

\section{Introduction}

Reflux esophagitis (RE) is an inflammation of the esophagus caused by reflux of gastric contents due to damage of the lower esophagus. It is characterized by a burning pain in the chest (so-called heartburn) and nausea after meals, and it includes reflux disease $[1,2]$. Though the exact mechanism underlying the occurrence of reflux esophagitis remains unknown, alcohol, smoking, obesity, stress, and various etiologies have been identified as the source of disease pathogenesis [3]. Reflux of gastric contents causes inflammation and ulceration, leading to the destruction of normal esophageal tissue $[4,5]$. According to the results of a recent study, oxidative stress has been shown to be a crucial pathogenesis of reflux esophagitis $[6,7]$. At the cellular level, reflux esophagitis causes acidosis and necrosis of the esophageal tissue proliferation of hydrogen ions to the mucosa due to oxidative stress [8]. All of these activities are activated by inflammatory and neutrophils decrease and reactive oxygen species (ROS), resulting in the penetration of active oxygen into all cells and the release of cytokines. Because the overproduction of ROS causes inflammation, antioxidants have been shown to block free radicals and prevent esophageal mucosal damage [9]. Due to oxidative stress, endothelial cells produce a large number of ROS through nicotinamide adenine 
dinucleotide phosphate (NADPH) in cell membranes. Intrinsic apoptosis induced by the explosion of ROS and inflammatory cytokines can cause mitochondrial energy metabolism disorders and lead to cell damage [10]. Currently, the existing treatments for RE include medical therapy like antacids, H2receptor antagonists, proton pump inhibitors (PPI), and surgical therapy [11]. The Gardeniae Fructus has been used in traditional Chinese medicine for various treatments such as cholagogue, anti-inflammatory, and antipyretic effects [12].

Gardeniae Fructus has been widely used as an herbal medicine for inflammation-related diseases and it has shown various pharmacological abilities such as anti-inflammatory effects and reduction of oxidative stress $[13,14]$. There has been no report on improvement through Gardeniae Fructus $50 \% \mathrm{EtOH}$ extract (GE) treatment in reflux-induced esophagitis. Therefore, we evaluated the antioxidative effects of the Gardeniae Fructus and investigated the effects on the reflux-induced esophagitis rats to explore the improvement effects of oxidative stress-related inflammation.

\section{Materials and Methods}

2.1. Materials. The protease inhibitor mixture solution and ethylenediaminetetraacetic acid (EDTA) were purchased from Wako Pure Chemical Industries, Ltd. (Osaka, Japan). Phenylmethylsulfonyl fluoride (PMSF) was purchased from Sigma Chemical Co. (St. Louis, MO, USA). $2^{\prime}, 7^{\prime}$-Dichlorofluorescein diacetate (DCF-DA) was obtained from Molecular Probes (Eugene, OR, USA). The pierce bicinchoninic acid (BCA) protein assay kit was obtained from Thermo Scientific (Rockford, IL, USA). ECL Western Blotting Detection Reagents and pure nitrocellulose membranes were supplied by GE Healthcare (Piscataway, NJ, USA). Rabbit polyclonal antibodies against nuclear factor-kappa B p65 (NF- $\kappa$ Bp65; $1: 1,000$, SC-372), nuclear factor-erythroid 2related factor 2 (Nrf-2; $1: 1,000$, SC-7228), heme oxygenase1 (HO-1; $1: 1,000$, SC-10789), superoxide dismutase (SOD; $1: 1,000$, SC-11407), catalase $(1: 1,000$, SC-50508), glutathione peroxidase-1/2 (GPx-1/2; $1: 1,000, \quad$ SC-30147), p $47^{\text {phox }}(1: 1,000$, SC-14015), Rac-1 (1:1,000, SC-217), Bax (1:1,000, SC-7480), and Bcl-2 (1:1,000, SC-7382); goat polyclonal antibodies against tumor necrosis factor-alpha (TNF- $\alpha ; 1: 1,000$, SC-1351), interleukin-1beta (IL-1 $\beta ; 1$ : 1,000, SC-1252); mouse monoclonal antibodies against cyclooxygenase-2 (COX-2; $1: 1,000$, SC-19999), inducible nitric oxide synthase (iNOS, $1: 1,000$, SC-7271), phosphorinhibitory kappa $b$ alpha $(p-\mathrm{I} \kappa \mathrm{b} \alpha ; 1: 1,000$, SC-8404), phosphor-extracellular signal-regulated kinase $1 / 2$ (p-ERK1/ $2 ; 1: 1,000$, SC-7383), phosphor-p38 (p-p38; 1:1,000, SC7973), phosphor c-Jun $\mathrm{N}$-terminal kinase (p-JNK, $1: 1000$, SC-6254), cytochrome c $(1: 1,000$, SC-13156), histone (1: 1,000 , SC-8030), and $\beta$-actin $(1: 1,000, \mathrm{SC}-4778)$ were purchased from Santa Cruz Biotechnology, Inc. (Santa Cruz, CA, USA). Monoclonal antibody against c-Jun (1:1000, \#2315) and polyclonal antibody against c-Fos $(1: 1,000$, \#4384) were obtained from Cell Signaling Technology Inc. (Cell Signaling, MA, USA). Mouse monoclonal antibodies against caspase-3 (1:1,000,3004-100) were purchased from BioVision Inc. (Mountain View, CA, USA). Rabbit polyclonal anti-reduced nicotinamide adenine dinucleotide phosphate oxidase 4 (NOX4) was purchased from Life SpanBioSciences (Seattle, WA, USA). Mouse monoclonal antibodies against survivin (1:1,000, NB 500-205) were purchased from Novus Biologicals (Littleton, CO, USA). Rabbit anti-goat $(1: 3,000$, SC-2774), goat anti-rabbit ( 1 : 3,000 , SC-2004), and goat anti-mouse (1:3,000, SC-2005) immunoglobulin G (IgG) horseradish peroxidase- (HRP-) conjugated secondary antibodies were acquired from Santa Cruz Biotechnology, Inc. (Santa Cruz, CA, USA). All other used chemicals and reagents were of an analytical grade and commercially available (Sigma Aldrich Co., Ltd., USA).

2.2. Test Material Preparation. Gardeniae Fructus was purchased from Ominherb Co. (Yeongcheon, Korea). The dried slices of Gardeniae Fructus ( $30 \mathrm{~g}$ ) were extracted with $50 \% \mathrm{EtOH}(300 \mathrm{~mL})$ at room temperature for $24 \mathrm{~h}$ and the solvent was evaporated in vacuo to gain powder with a yield of $23.12 \%$, by weight.

\subsection{Analysis of Gardeniae Fructus by HPLC Chromatogram.} The $50 \%$ EtOH extract of Gardeniae Fructus $(5.11 \mathrm{mg}$ ) was dissolved in $50 \mathrm{~mL}$ of $70 \%$ ethanol with multivortexing. We injected $1 \mu \mathrm{L}$ of the sample into high-performance liquid chromatography (HPLC) using Agilent analytical $0.25 \times 460 \mathrm{~mm}, 5$ microns, with a column temperature of $30^{\circ} \mathrm{C}$, mobile phase component acetonitrile-water $(\mathrm{v} / \mathrm{v}, 9$ : 91). The flow rate was $1.0 \mathrm{~mL} / \mathrm{min}$. The UV absorbance from $240 \mathrm{~nm}$ was monitored using an Agilent 2960 series photodiode array detector from Waters Co. (Manchester, UK). All peaks were assigned by carrying out coinjection tests with authentic samples and comparing those with the UV spectral data. The major component of Gardeniae Fructus was geniposide, and the measurement was repeated two times. Representative HPLC results are illustrated in Figure 1.

2.4. DPPH Radical Scavenging Activity of GE. The antioxidant activity determination of GE was performed by the $\mathrm{DPPH}$ radical scavenging according to the method of Hatano et al. [15]. The reduction of the stable purple free radical DPPH to the yellow hydrazine is achieved by trapping the unpaired electrons, and the degree of discoloration indicates the scavenging activity of samples [16]. $100 \mu \mathrm{L}$ of an ethanolic solution of GE (blank: $100 \mu \mathrm{L}$ of ethanol) was added to $100 \mu \mathrm{L}$ of an ethanolic solution of $\mathrm{DPPH}(60 \mu \mathrm{M})$ using a 96 -well microtiter plate. The ascorbic acid (standard sample) and GE were prepared for eight concentrations $(0.5,1,2.5,5,10,25,50,100,250,500$, and $1000 \mu \mathrm{g} / \mathrm{mL}$ ). After mixing gently and leaving the mixture to stand for $30 \mathrm{~min}$ at room temperature, the optical density was determined using a Microplate Reader, model infinite M200 PRO (Tecan, Austria). The mixture was measured spectrophotometrically at $540 \mathrm{~nm}$. The antioxidant activity of 4 evidence-based complementary and alternative medicine samples was expressed in terms of the $\mathrm{IC}_{50}$ (micromolar concentration required to inhibit DPPH radical formation by $50 \%$, calculated from the log-dose inhibition curve). 


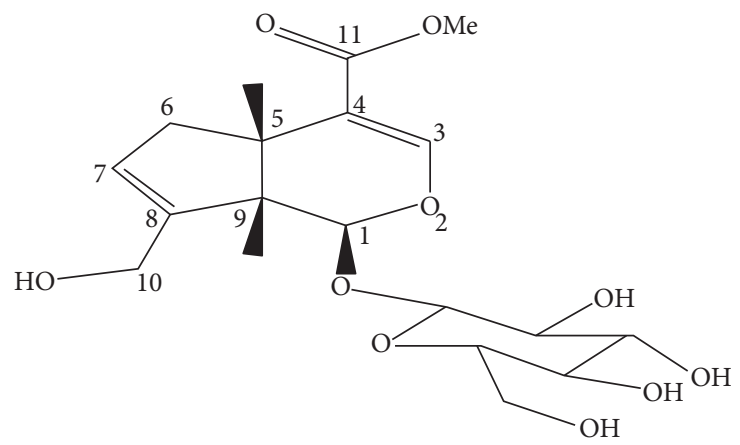

(a)

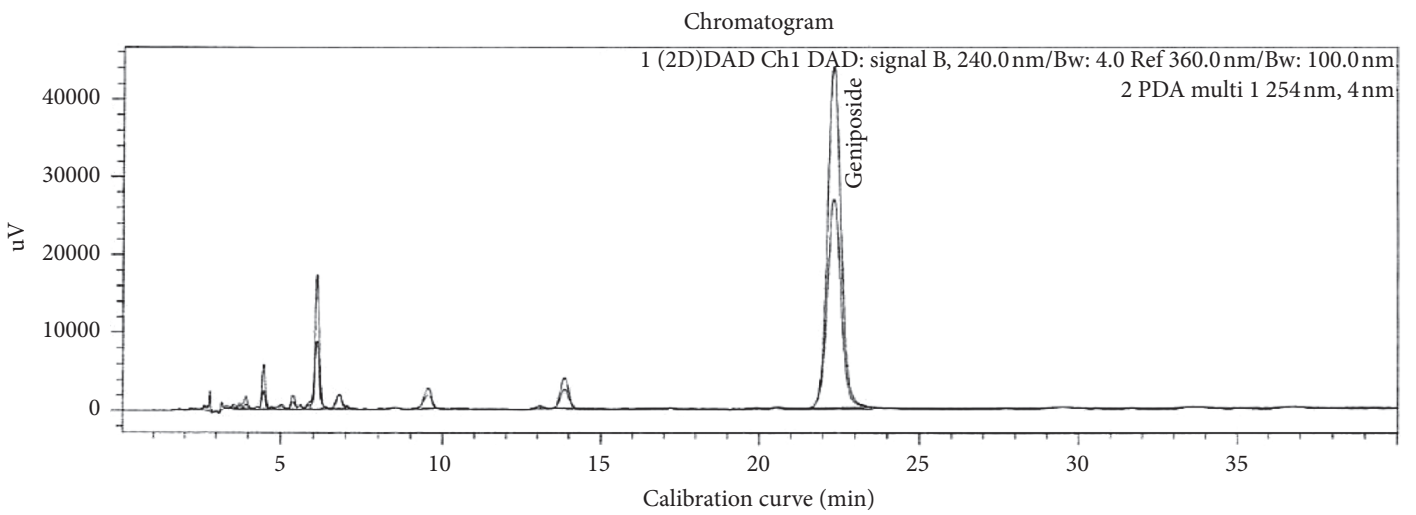

(b)

Figure 1: HPLC profile of GE. Geniposide (C17H24O10:388.37) (a), HPLC profile of geniposide (b).

DPPH radical scavenging activity $(\%)=\left[1-\left(\frac{\text { Asample }}{\text { Ablank }}\right)\right] \cdot 100$.

2.5. ABTS Radical Scavenging Activity of GE. The ABTS radical scavenging activity of the different extracts was measured according to the modified method of Re et al. [17]. The ABTS stock solution was dissolved in water to a $7.4 \mathrm{mM}$ concentration. The ABTS radical cation was produced by reacting ABTS stock solution with $2.45 \mathrm{mM}$ potassium persulfate and allowing the mixture to stand for $14 \mathrm{~h}$ at room temperature in the dark. The ABTS solution was diluted with ethanol to obtain an absorbance of $0.70 \pm 0.02$ at $415 \mathrm{~nm}$. After adding $95 \mu \mathrm{L}$ of diluted ABTS solution $(A 415 \mathrm{~nm}=0.70 \pm 0.02)$ to $5 \mu \mathrm{L}$ of sample, we left the mixture at room temperature for $15 \mathrm{~min}$ in the dark. The absorbance at $415 \mathrm{~nm}$ was measured using a Microplate Reader, model infinite M200 PRO (Tecan, Austria). The blank was prepared in the same manner, except that distilled water was used instead of the sample.

ABTS radical scavenging activity $(\%)=\left[1-\left(\frac{\text { Asample }}{\text { Ablank }}\right)\right] \cdot 100$.

2.6. Experimental Animals and Treatment. Animal experiments were carried out according to the "Guidelines for Animal Experimentation" approved by the Ethics
Committee of the Daegu Haany University (Approval number 2018-003). Six-week-old male Sprague-Dawley rats were purchased from Samtako (Eumseong, Korea). Rats were maintained under a $12 \mathrm{~h}$ light/dark cycle and housed at a controlled temperature $\left(24 \pm 2^{\circ} \mathrm{C}\right.$ ) and humidity (about $55 \%)$. After adaptation (1 week), a total of 24 SD rats were randomly divided into 4 groups ( $n=6$ per group). The rats were fasted for $18 \mathrm{~h}$ prior to surgical procedures and kept in raised mesh-bottom cages to prevent coprophagy but were provided free access to food thereafter. The rats were anaesthetized with an injection of Zoletil $0.75 \mathrm{mg} / \mathrm{kg}$ (Virbac S. A., France). A midline laparotomy was performed to expose the stomach; both the pylorus and the transitional junction between the forestomach and the corpus were exposed and then ligated with a 2-0 silk thread without a pyloric ring, employing the method originally proposed by Omura et al. [18]. Group one included normal rats (Nor). Group two included RE control rats (Con). Group three included the RE control rats treated with GE $50 \mathrm{mg} / \mathrm{kg}$ (GL). Group four included the RE control rats treated with GE $100 \mathrm{mg} / \mathrm{kg}(\mathrm{GH})$. The normal and RE control rat groups were given water, while the other groups were orally given GE at a dose of 50 and $100 \mathrm{mg} / \mathrm{kg}$ body weight. The administration of water or GE in rats was provided using a stomach tube only one time $1 \mathrm{~h} 30 \mathrm{~min}$ before abdominal surgery. The rats in all groups were sacrificed $5 \mathrm{~h}$ after the surgery. The entire esophagus was removed immediately and examined for gross mucosal injury. The esophageal tissue was then immediately frozen in liquid nitrogen, serum was extracted 
from the collected blood, and both were subsequently stored at $-80^{\circ} \mathrm{C}$ with the serum samples until the analysis.

2.7. Esophageal Lesion Score. After euthanasia, the esophagus of each rat was cut in a longitudinal direction from the gastroesophageal junction to the pharynx using scissors. The inner mucous was washed away with $0.9 \%$ sodium chloride $(\mathrm{NaCl})$ and the remaining tissue was laid out on paper. Then, the dissected esophagus was photographed using an optical digital camera (Sony, Tokyo, Japan) and analyzed using the i-Solution Lite software program.

The gross mucosal damage ratio was calculated as follows: the gross mucosal damage ratio

$$
(\%)=\left[\frac{\text { width of area with esophageal mucosal damage }\left(\mathrm{mm}^{2}\right)}{\text { width of total area of esophagus }\left(\mathrm{mm}^{2}\right)}\right] \text {. }
$$

2.8. Histological Examination in the Esophagus. For microscopic evaluation, the opened esophagus was cut to isolate the middle segment. This segment was fixed in $10 \%$ neutralbuffered formalin and, after embedding in paraffin, cut into $2 \mu \mathrm{m}$ sections and stained using hematoxylin and eosin (H\&E) and periodic acid schiff (PAS). The stained slices were subsequently observed under an optical microscope and analyzed using the i-Solution Lite software program (Innerview Co., Korea).

2.9. Measurement of ROS Level in the Serum. The ROS levels were measured by using the method described by Ali et al. [19]. A total of $25 \mathrm{mM}$ DCF-DA was added to the serum sample. After incubation for $30 \mathrm{~min}$, changes in fluorescence were determined at an excitation wavelength of $486 \mathrm{~nm}$ and an emission wavelength of $530 \mathrm{~nm}$.

\subsection{Preparation of Cytosol and Nuclear Fractions.} Protein extraction was performed according to the method of Komatsu with minor modifications [20]. Esophageal tissues for cytosol fraction were homogenized with ice-cold lysis buffer A $(250 \mathrm{~mL})$ containing $10 \mathrm{mM}$ HEPES ( $\mathrm{pH} 7.8)$, $10 \mathrm{mM} \mathrm{KCl}, 2 \mathrm{mM} \mathrm{MgCl} 2,1 \mathrm{mM}$ DTT, $0.1 \mathrm{mM}$ EDTA, $0.1 \mathrm{mM}$ PMSF, and $1250 \mu \mathrm{L}$ protease inhibitor mixture solution. The homogenate incubated at $4^{\circ} \mathrm{C}$ for $20 \mathrm{~min}$. And then $10 \%$ NP-40 was added and mixed well. After centrifugation $\left(13,400 \times g\right.$ for $2 \mathrm{~min}$ at $\left.4^{\circ} \mathrm{C}\right)$ using Eppendorf $5415 \mathrm{R}$ (Hamburg, Germany), the supernatant liquid (cytosol fraction) was separated by a new e-tube. The left pellets were washed twice by buffer A and the supernatant was discarded. Next, the pellets were suspended with lysis buffer C $(20 \mathrm{~mL})$ containing $50 \mathrm{mM}$ HEPES (pH 7.8), $50 \mathrm{mMKCl}, 300 \mathrm{mM}$ $\mathrm{NaCl}, 1 \mathrm{mM}$ DTT, $0.1 \mathrm{mM}$ EDTA, $0.1 \mathrm{mM}$ PMSF, 1\% (v/v) glycerol, and $100 \mu \mathrm{L}$ protease inhibitor mixture solution suspended and incubated at $4^{\circ} \mathrm{C}$ for $30 \mathrm{~min}$. After centrifugation $\left(13,400 \times g\right.$ for $10 \mathrm{~min}$ at $\left.4^{\circ} \mathrm{C}\right)$, the nuclear fraction was prepared to collect the supernatant. Both cytosol and nuclear fractions were kept at $-80^{\circ} \mathrm{C}$ before the analysis.
2.11. Immunoblot analyses. To estimate nuclear factor-erythroid 2-related factor 2 (Nrf2), NF- $\kappa$ Bp65, c-Jun, c-Fos, and histone levels, $15 \mu \mathrm{g}$ of protein from each nuclear fraction was separated using $8-10 \%$ sodium dodecyl sulfate polyacrylamide gel electrophoresis (SDS-PAGE). Separated proteins were transferred onto a nitrocellulose membrane, blocked with $5 \%(\mathrm{w} / \mathrm{v})$ skim milk solution for $1 \mathrm{~h}$, and then incubated with primary antibodies (against Nrf2, NF- $\kappa$ Bp65, and histone) overnight at $4^{\circ} \mathrm{C}$. The blots were washed and incubated with anti-rabbit or anti-mouse IgG horseradish peroxidase(HRP-) conjugated secondary antibody for $1 \mathrm{~h}$. In addition, $10 \mu \mathrm{g}$ of protein of each cytosolic fraction of $\mathrm{HO}-1$, catalase, GPx-1/2, I $\kappa \mathrm{B} \alpha, \mathrm{p}-\mathrm{I} \kappa \mathrm{B} \alpha, \mathrm{COX}-2$, iNOS, TNF- $\alpha$, IL- $1 \alpha$, NOX 4 , p47 ${ }^{\text {phox }}$, Rac-1, keap1, p38, p-p38, ERK, p-ERK, JNK, p-JNK, survivin, cytochrome $\mathrm{c}$, caspase- $3, \mathrm{Bax}, \mathrm{Bcl}-2$, and $\beta$-actin was separated using $8-15 \%$ SDS-PAGE. The antigen-antibody complex was visualized using ECL Western Blotting Detection Reagents and detected using chemiluminescence with the Sensi-Q 2000 Chemidoc imager (LugenSci Co., Ltd., Gyeonggi-do, Korea). Band intensities were measured using ATTO densitograph software (ATTO Corporation, Tokyo, Japan) and quantified as the ratio to histone or $\beta$-actin. The protein levels of the groups are expressed relative to those of the normal rats (represented as 1).

2.12. Statistical Analysis. The data are expressed as the means \pm standard error of the mean (SEM). Significance was assessed using a one-way analysis of variance (ANOVA) followed by Dunnett's multiple comparison test using the statistical package for the social sciences (SPSS) version 22.0 software (SPSS Inc., Chicago, IL, USA). Furthermore, $p$ values $<0.05$ were considered significant.

\section{Results and Discussions}

In modern medicine, $\mathrm{RE}$ is a multifactorial disorder and esophageal pathology most frequently occurring in gastrointestinal disease and has a significant impact on the quality of life and medical costs $[21,22]$. The main pathogenesis of $\mathrm{RE}$ is complex and diverse, including esophageal mucosal irritability, decreased esophageal capacity, decreased esophageal sphincter function, and gastric motility disorders [23]. The regurgitation of stomach contents is known to cause impairment, inflammation, ulceration, and necrosis of the normal squamous epithelium of the esophagus [24]. Reflux esophagitis is associated with esophageal stricture and Barrett's esophagus and is likely to develop into esophageal cancer [25]. Drugs such as histamine type II receptor antagonists (H2-RA) or proton pump inhibitors (PPI) have been used to treat reflux esophagitis effectively, but many patients fail to complete mucosal healing and progress to a complex condition or suffer [26].

Recently, antioxidants have been shown to be effective in reflux esophagitis by suppressing symptoms of esophageal mucosa due to excessive free radicals produced in the esophagus [27]. The Gardeniae Fructus has been demonstrated as an effective pharmacological action, including a protective activity against oxidative damage, as well as having 
cytotoxic and anti-inflammatory effects [28]. Geniposide, the main compound of Gardeniae Fructus, has been reported to have a significant effect on inflammation, ulceration, and diabetes [29]. Herbal remedies are considered to be harmless and nontoxic to humans, suggesting alternatives to existing medicines [30]. The components of the major compound (geniposide) were detected from the Gardeniae Fructus extract. Representative HPLC results are illustrated in Figure 1. The amount of geniposide was as follows: GE: $0.154 \mathrm{~g} / \mathrm{mL}$. Geniposide has been shown to reduce inflammatory cytokines in intestinal diseases [31]. In this study, we suggest that geniposide may reduce inflammation in reflux esophagitis.

The result of this study was to investigate the antioxidant effect of $50 \%$ ethanol extracts of Gardeniae Fructus on the improvement of reflux esophagitis. The DPPH radical scavenging ability and the ABTS radical scavenging test are methods for measuring the antioxidative activity of a sample by an in vitro assay method [32]. In this respect, the DPPH and ABTS radical scavenging $\mathrm{IC}_{50}$ values of the $\mathrm{GE}$ were measured $(41.86 \pm 1.35$ and $89.57 \pm 1.78 \mu \mathrm{g} / \mathrm{mL}$, resp.) and $\mathrm{L}$-ascorbic acid was used as a standard substance in terms of $\mathrm{IC}_{50}$ values $(1.15 \pm 0.06$ and $3.67 \pm 0.07 \mu \mathrm{g} / \mathrm{mL}$, resp. $)$, used as an antioxidant reference molecule. The in vitro antioxidant analysis showed that the GE could prevent oxidative stress induced by RE (Figure 2).

Esophageal mucosa is one of the important defense mechanisms through the epithelium (mucous and bicarbonate ions), the epithelial cells (epithelial cells), and the deep epidermis (blood vessel), and the mucosal layer is damaged by the refluxed stomach contents [33]. The esophageal lesion score was significantly increased in the control group compared to the normal group, but, compared with the control group, there was a dose-dependent decrease in the GE treated group (Figure 3).

Chronic acid reflux esophagitis is contrasted with the features of hemorrhage, erythema, and multiple erosion in modeled rats and acute reflux esophagitis [34]. In the normal group, lesions were not observed in the esophageal mucosa but the esophageal mucosa was found to be damaged in the reflux esophagus induced tissue. The esophagus showed thickening of the basal layer, inflammatory cell infiltration into the mucosal layer, and exfoliated epithelial cells [2]. Importantly, in the case of the GE group, a concentrationdependent decrease of the squamous layer cell damage and recovery from the inflammation were observed. The degree of damage of esophageal mucosa was dose dependent. Especially, the group treated with $100 \mathrm{mg} / \mathrm{kg}$ of Gardeniae Fructus extract showed significant improvement (Figure 4).

The effects of GE treatment were confirmed by the H\&E staining histological characterization in esophagus tissue. In addition, PAS staining showed goblet cells with regular mucosal construction secreting mucus in the GL and GH groups compared to the control group. This observation suggests that GE treatment can be effective against acute reflux esophagitis by promoting mucus secretion (Figure 5).

The production of ROS causes cellular damage, and it has been reported to play a role in the pathogenesis of various gastrointestinal diseases $[35,36]$. ROS produced by gastric reflux has been shown to cause damage to the esophagus, and these results suggest that the antioxidant activity can prevent tissue damage [37]. In the present study, the elevated levels of serum ROS were significantly decreased lower to the levels of the control group, both GL and GH $(p<0.001)$ (Figure 6(a)).

Nicotinamide adenine dinucleotide phosphate (NADPH) oxidase is an enzyme that catalyzes the formation of ROS [38]. NADPH is a factor associated with tissue damage in inflammatory diseases, with excess production of ROS through NOX4, p47 $7^{\text {phox }}$, and Rac-1 [39]. The protein expressions NOX4, $447^{\text {phox }}$, and Rac-1, the markers of NADPH oxidase activity, in the esophagus were significantly augmented in the RE control group. However, the GL and $\mathrm{GH}$ treated groups had significantly downregulated NOX4 and $\mathrm{p} 47^{\text {phox }}$ whereas Rac- 1 tended to decrease with the dosedependence of the GL and GH treatment groups (Figure 6).

ROS is generally reported to be neutralized by antioxidant enzymes [40]. In general, Nrf-2 is present in the cytoplasm and oxidative stress induces Nrf-2 translocation into the nucleus. Nrf-2 binds to antioxidant response elements and induces transcription of antioxidant enzymes such as HO-1, catalase, and GPx [41]. The oral administration of GE showed a significant dose-dependent increase in the expression level of Nrf-2 and a significant dose-dependent increase in the activity of $\mathrm{HO}-1$ and catalase. GPx-1/2 activity was also significantly increased in the GH group compared to the control group. The administration of GE suggests that it can upregulate antioxidant factors and effectively remove oxidative stress induced by reflux esophagitis (Figure 7).

Mitogen-activated protein kinase (MAPK) is the most commonly studied pathway for inflammatory signals. This pathway is activated when extracellular or intracellular stress is present [42]. MAPK (p38, ERK, and JNK) makes a role in making inflammation through the interaction of three pathway factors [43]. JNK activates and phosphorylates c-Jun by oxidative stress [44]. MAPK signaling is associated with nuclear factor $\mathrm{NF}-\kappa \mathrm{B}$, one of the transcription factors. In particular, the phosphorylation of p38 and ERK induces activation of NF- $\kappa \mathrm{B}$ with many direct and indirect interactions $[45,46]$. Both GL and GH treatment groups showed significant results, indicating a role in reducing inflammatory factors (Figure 8).

$\mathrm{NF}-\kappa \mathrm{B}$ regulates immune and inflammatory responses as well as important nuclear transcription factors and regulates several important physiological processes. Due to various stimuli, $\mathrm{I} \kappa \mathrm{B} \alpha$ binds to NF- $\kappa \mathrm{B}$ and inhibits $\mathrm{NF}-\kappa \mathrm{B}$ migration into the nucleus and inhibits its activity [47]. NF- $\kappa \mathrm{B}$ participates in controlling the activation of various proinflammatory mediators such as iNOS and COX-2 and cytokines such as IL- $1 \beta$ and TNF- $\alpha$ [48]. Protein expression of NF- $\kappa \mathrm{Bp} 65$ and $\mathrm{p}-\mathrm{I} \kappa \mathrm{B} \alpha$ was significantly decreased in the GL and GH treated groups compared to the control group. In the case of COX-2, iNOS, TNF- $\alpha$, and IL- $1 \beta$, the GE treatment group showed a significant decrease in concentration-dependent manner (Figure 9).

The development of inflammation by overexpression of ROS causes damage to the cell and increases apoptosis of the cell [49]. It is known that it is involved in the induction of cell death through the activation of survivin, cytochrome c, Bax, 


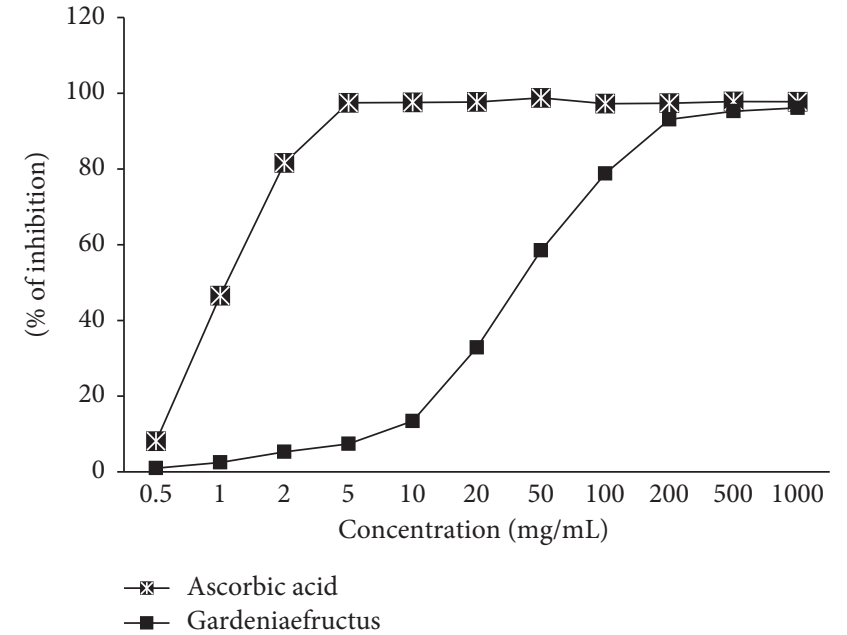

(a)

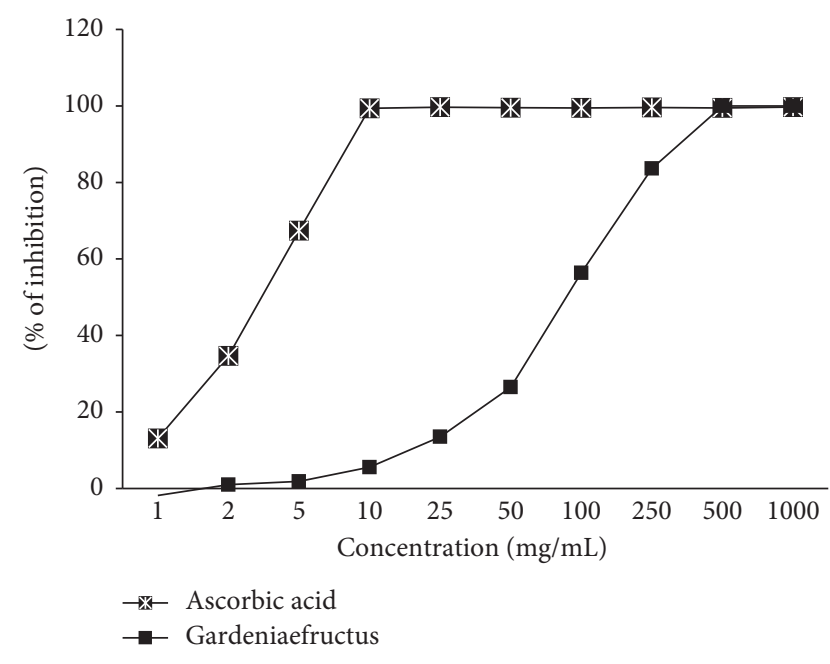

(b)

FIGURE 2: DPPH radical scavenging activity (a) and ABTS radical scavenging activity (b) of GE; each experiment was run in triplicate.

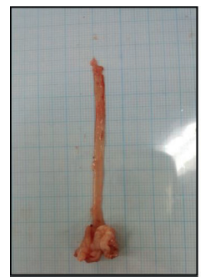

Nor

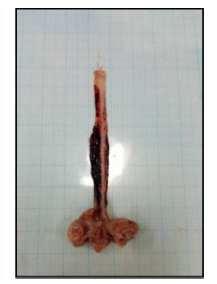

Con

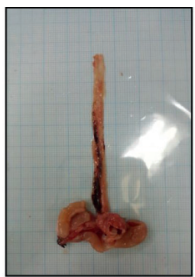

GL

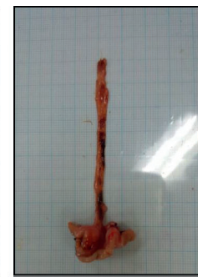

$\mathrm{GH}$

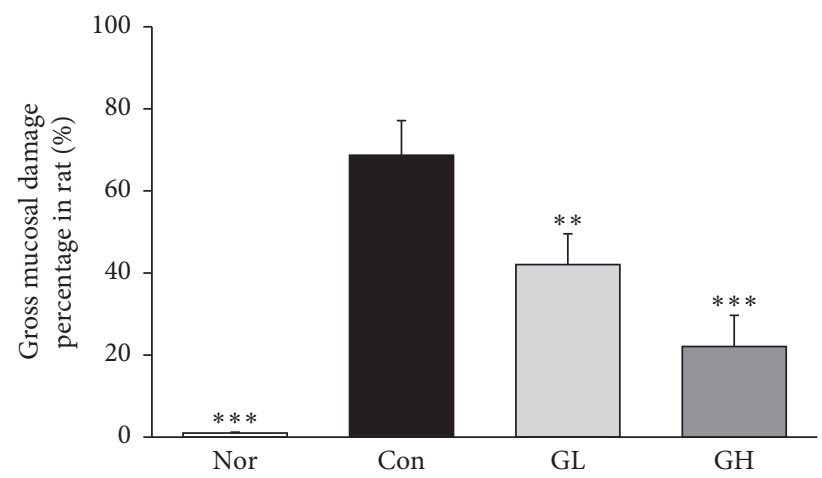

(b)

Figure 3: (a) Effects of GE on optical change of esophagus tissues and (b) effects on the gross mucosal injury ratio change of esophagus tissues of reflux esophagitis rats. Nor: normal rats, Con: reflux esophagitis control rats, GL: GE $50 \mathrm{mg} / \mathrm{kg}$ treated reflux esophagitis rats, and GH: GE $100 \mathrm{mg} / \mathrm{kg}$ treated reflux esophagitis rats. All data are expressed means $\pm \mathrm{SEM},(n=6)$ rats per group. Significance: ${ }^{* *} p<0.01,{ }^{* * *} p<0.001$ versus RE control rat values.
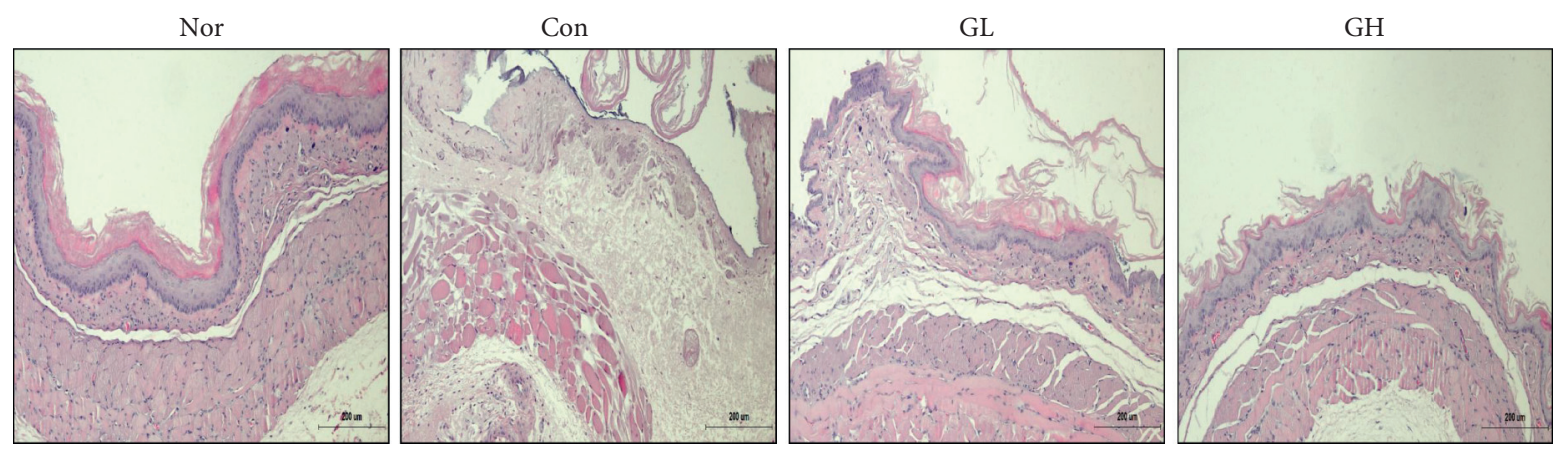

(a)

Figure 4: Continued. 

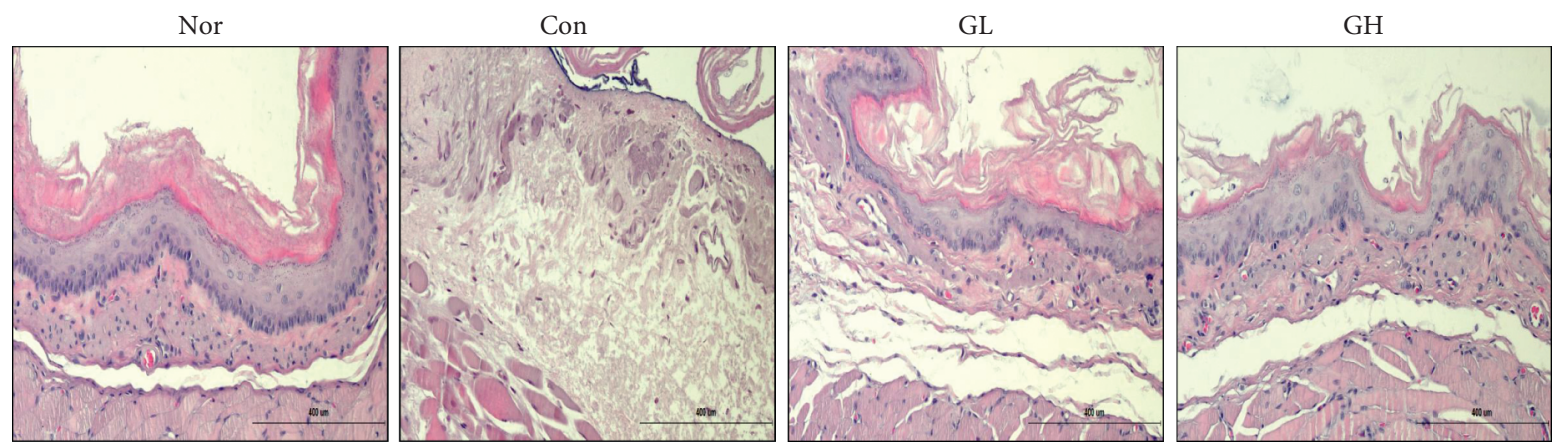

(b)

FIGURE 4: The effect of GE on the histopathological change epididymis esophagus tissues of RE rats. Esophagus tissues were stained with H\&E (Original magnification $\times 200$ and $\times 400$ ). Nor: normal rats, Con: reflux esophagitis control rats, GL: GE $50 \mathrm{mg} / \mathrm{kg}$ treated reflux esophagitis rats, and GH: GE $100 \mathrm{mg} / \mathrm{kg}$ treated reflux esophagitis rats.
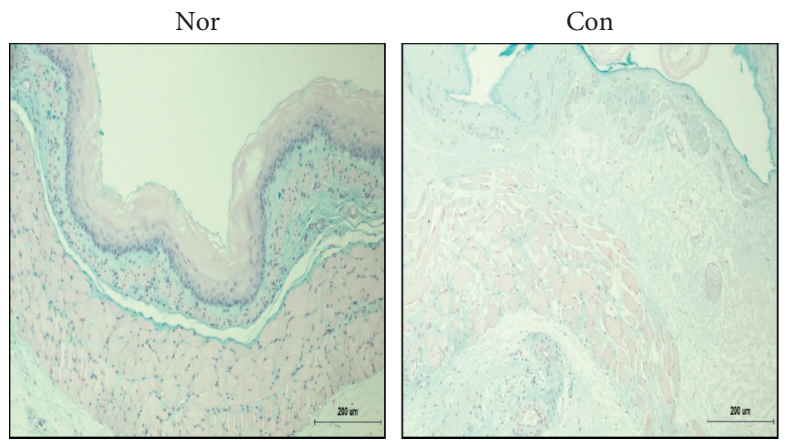

(a)
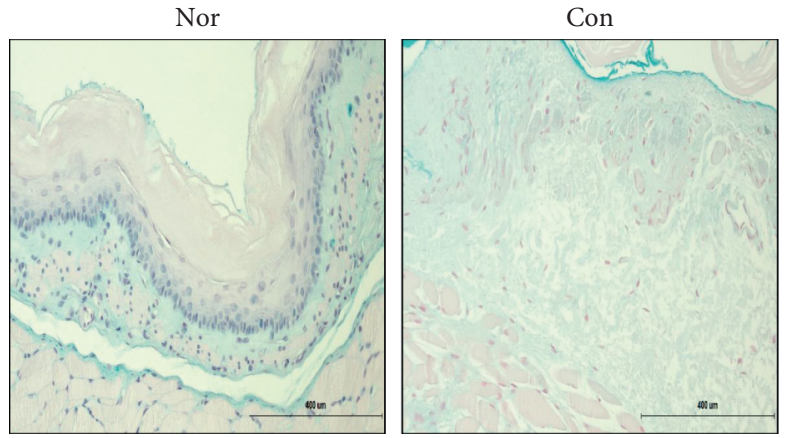

GL
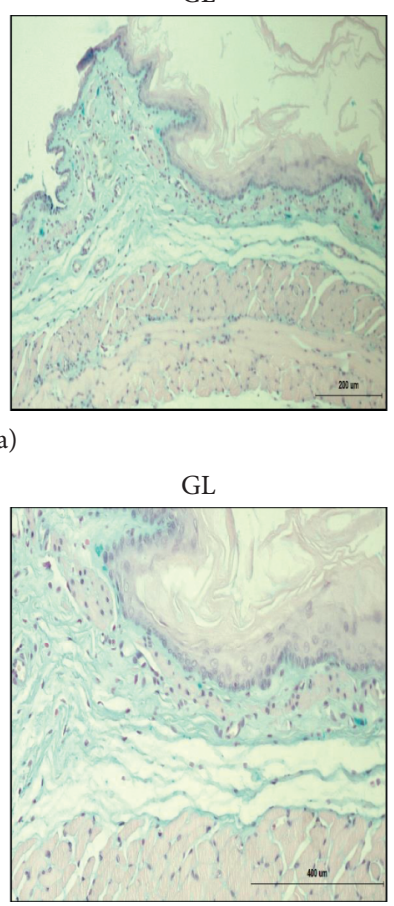

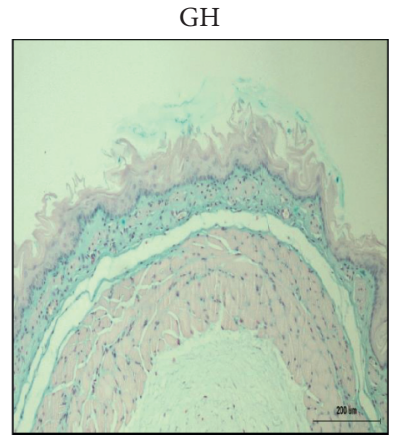

$\mathrm{GH}$

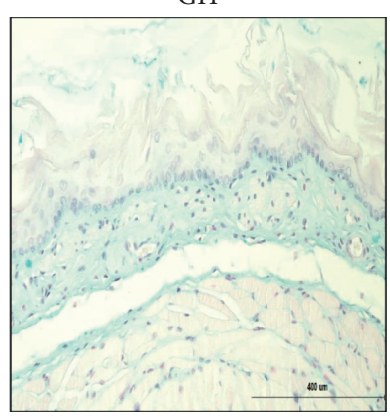

(b)

FIGURE 5: The effect of GE on the histopathological change epididymis esophagus tissues of RE rats. Esophagus tissues were stained with PAS (Original magnification $\times 200$ and $\times 400$ ). Nor: normal rats, Con: reflux esophagitis control rats, GL: GE $50 \mathrm{mg} / \mathrm{kg}$ treated reflux esophagitis rats, and GH: GE $100 \mathrm{mg} / \mathrm{kg}$ treated reflux esophagitis rats.
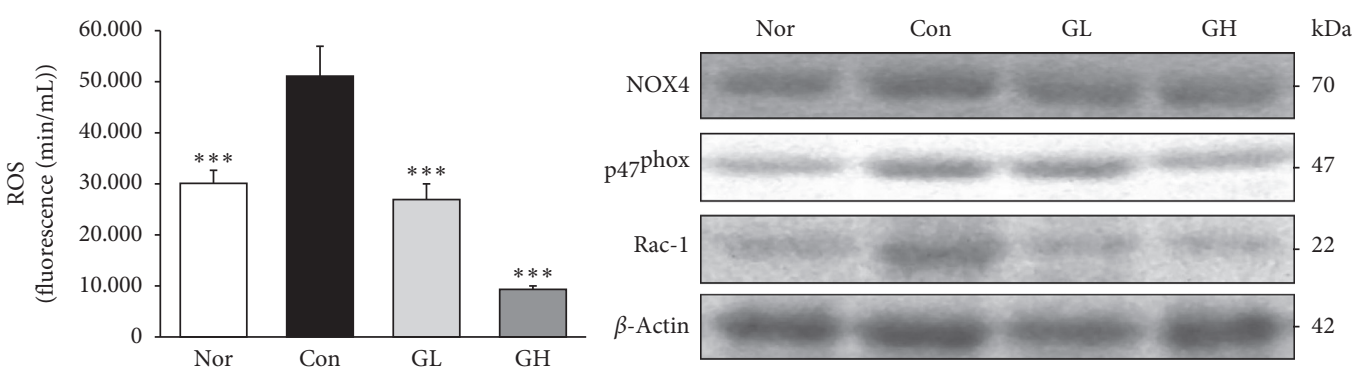

(a)

Figure 6: Continued. 

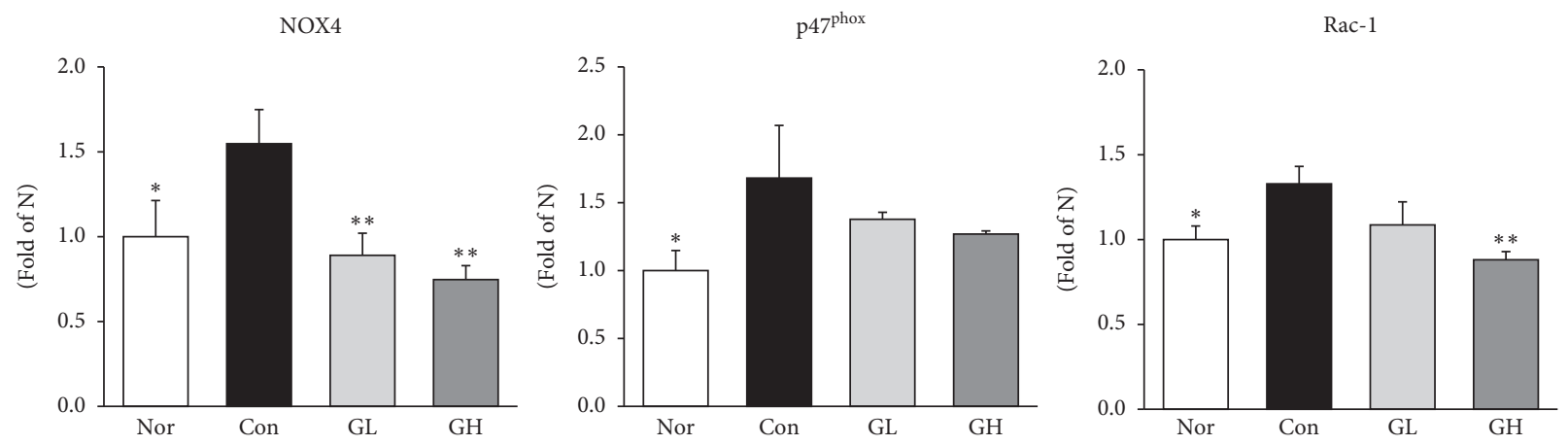

(b)

FIGURE 6: GE decreased serum ROS and NADPH oxidase activity protein expressions. (a) Serum ROS. (b) NOX4, p47 ${ }^{\text {phox }}$, and Rac-1 protein expressions. Nor: normal rats, Con: reflux esophagitis control rats, GL: GE $50 \mathrm{mg} / \mathrm{kg}$ treated reflux esophagitis rats, and GH: GE $100 \mathrm{mg} / \mathrm{kg}$ treated reflux esophagitis rats. All data are expressed means \pm SEM, $(n=6)$ rats per group. Significance: ${ }^{*} p<0.05,{ }^{* *} p<0.01,{ }^{* * *} p<0.001$ versus RE control rat values.

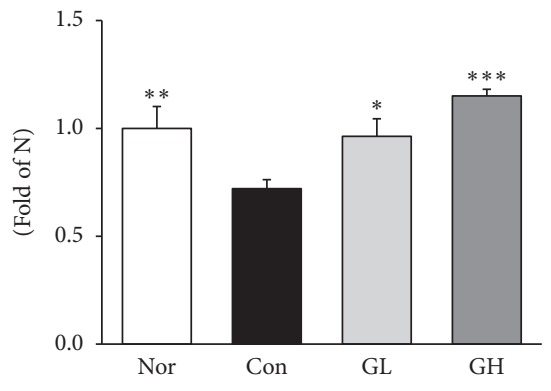

(a)

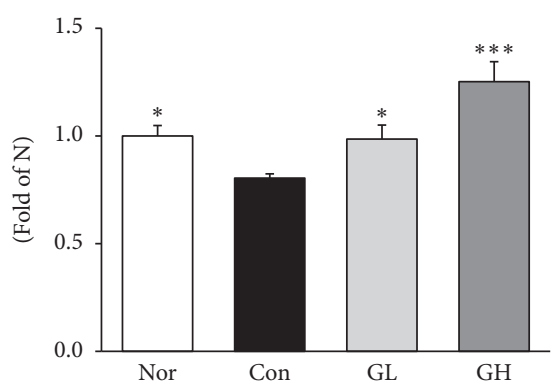

(c)

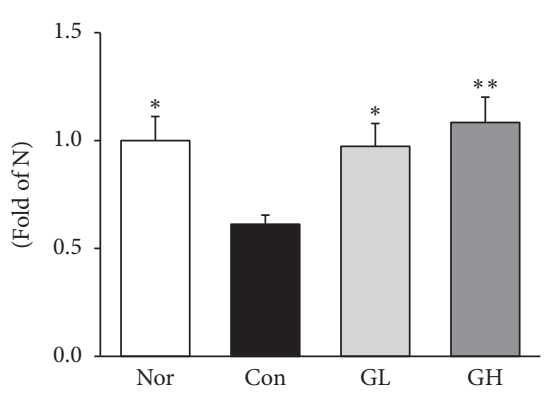

(b)

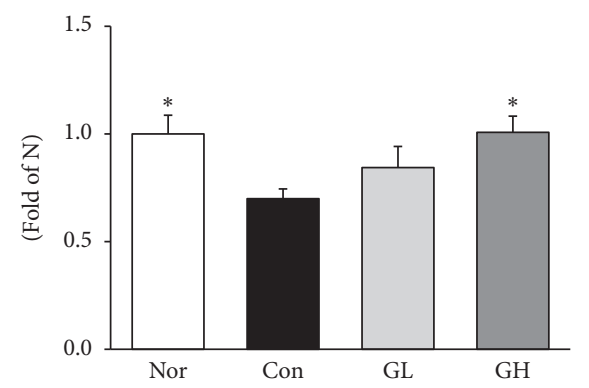

(d)

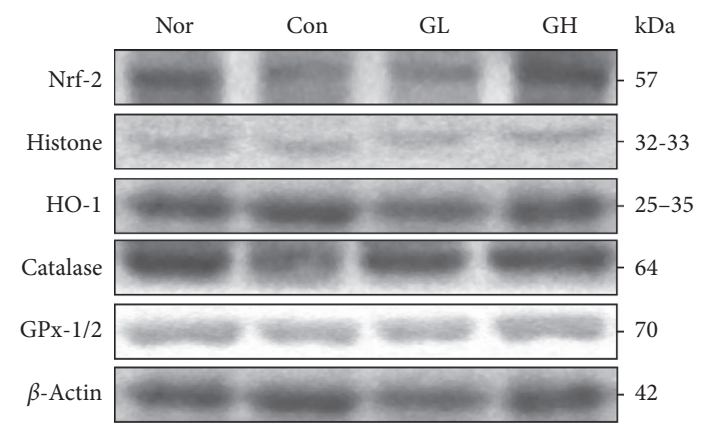

(e)

Figure 7: Antioxidant enzyme-related protein expressions in the esophagus. Western blot analysis of (a) Nrf-2, (b) HO-1, (c) catalase, and (d) GPx-1/2 expression. Nor: normal rats, Con: reflux esophagitis control rats, GL: GE $50 \mathrm{mg} / \mathrm{kg}$ treated reflux esophagitis rats, and GH: GE $100 \mathrm{mg} / \mathrm{kg}$ treated reflux esophagitis rats. (e) All data are expressed means \pm SEM, $(n=6)$ rats per group. Significance: ${ }^{*} p<0.05,{ }^{* *} p<0.01,{ }^{* * *} p<0.001$ versus RE control rat values. 


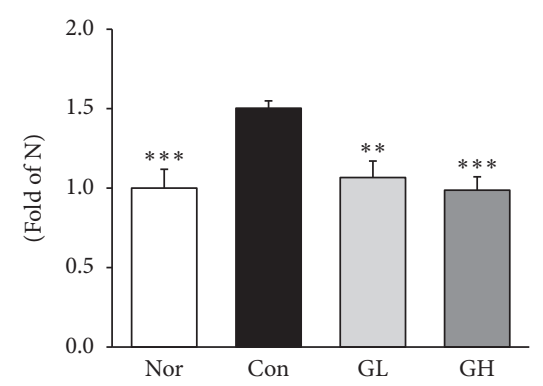

(a)

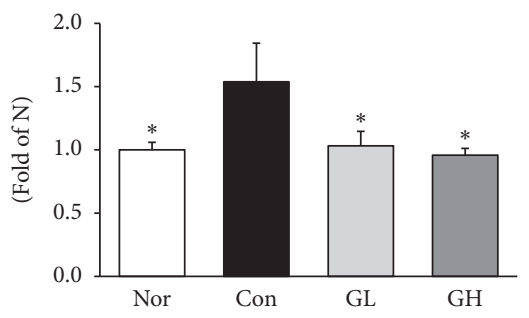

(d)

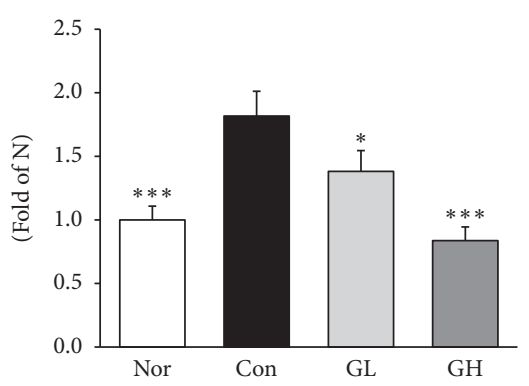

(b)

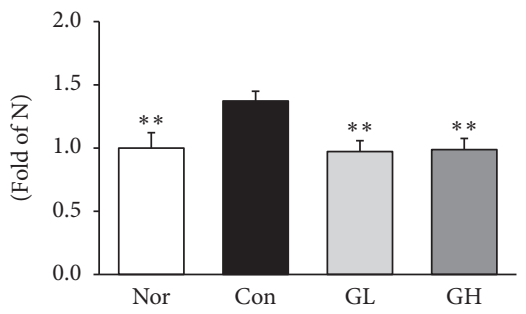

(e)

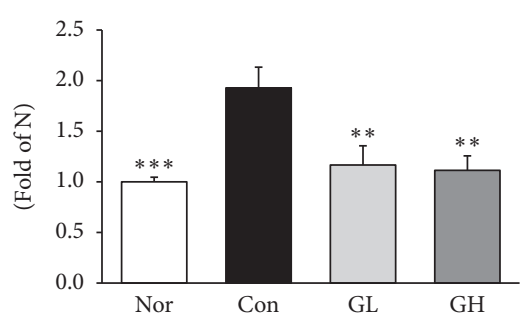

(c)

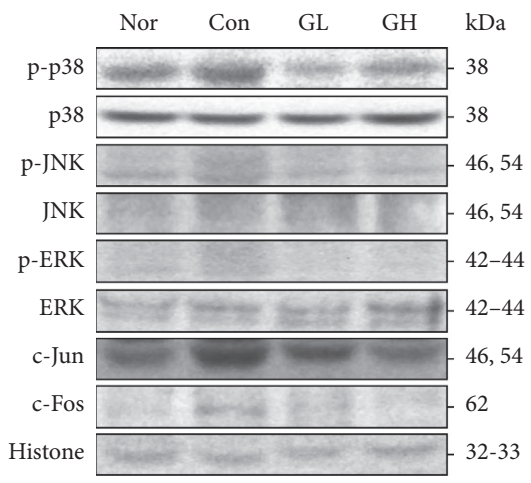

(f)

Figure 8: Western blot analysis of (a) c-Jun, (b) c-Fos, (c) p-p38, (d) p-JNK, and (e) p-ERK expressions. Nor: normal rat, Con: reflux esophagitis control rats, GL: GE $50 \mathrm{mg} / \mathrm{kg}$ treated reflux esophagitis rats, and GH: GE $100 \mathrm{mg} / \mathrm{kg}$ treated reflux esophagitis rats. (f) All data are expressed means \pm SEM, $(n=6)$ rats per group. Significance: ${ }^{*} p<0.05,{ }^{* *} p<0.01,{ }^{* * *} p<0.001$ versus RE control rat values.

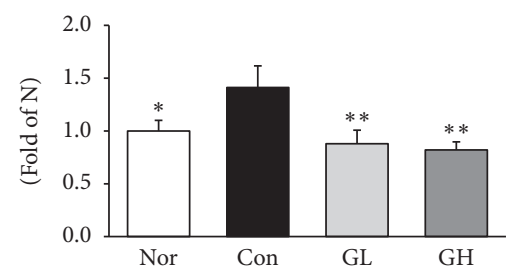

(a)

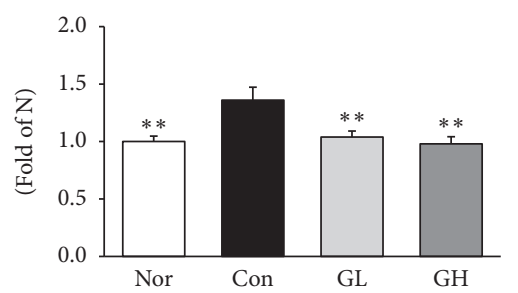

(d)

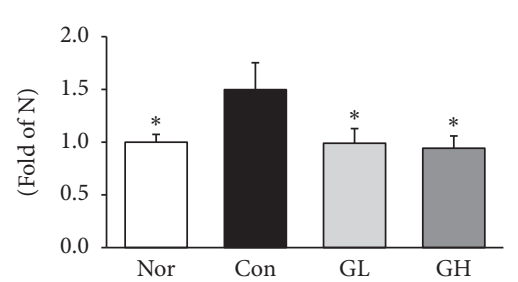

(b)

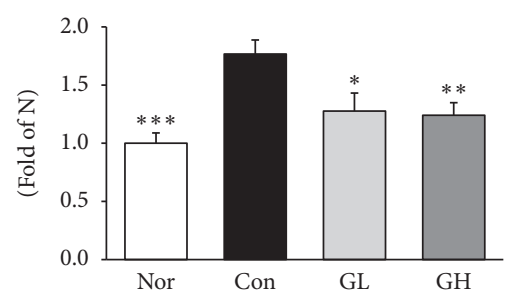

(e)

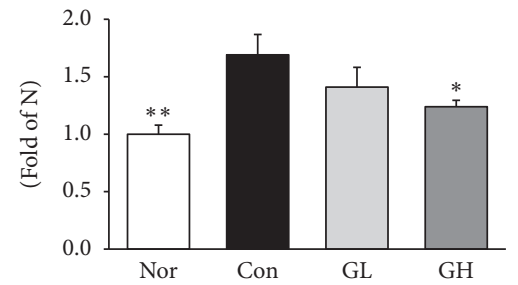

(c)

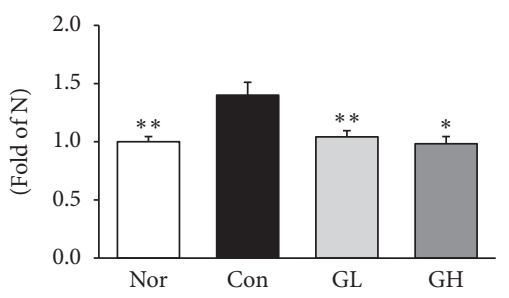

(f)

Figure 9: Continued. 


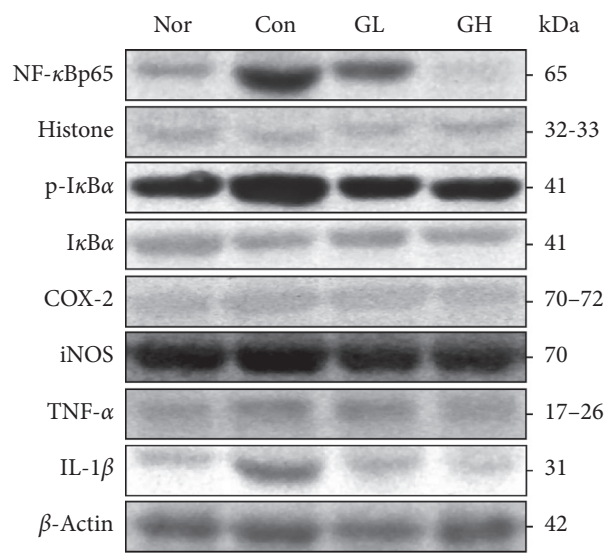

$(\mathrm{g})$

Figure 9: Western blot analysis of (a) NF- $\kappa$ Bp65, (b) p-I $\kappa$ B $\alpha$, (c) COX-2, (d) iNOS, (e) TNF- $\alpha$, and (f) IL- $1 \beta$ expressions. Nor: normal rats, Con: reflux esophagitis control rats, GL: GE $50 \mathrm{mg} / \mathrm{kg}$ treated reflux esophagitis rats, and GH: GE $100 \mathrm{mg} / \mathrm{kg}$ treated reflux esophagitis rats. (g) All data are expressed means \pm SEM, $(n=6)$ rats per group. Significance: ${ }^{*} p<0.05,{ }^{* *} p<0.01,{ }^{* * *} p<0.001$ versus RE control rat values.

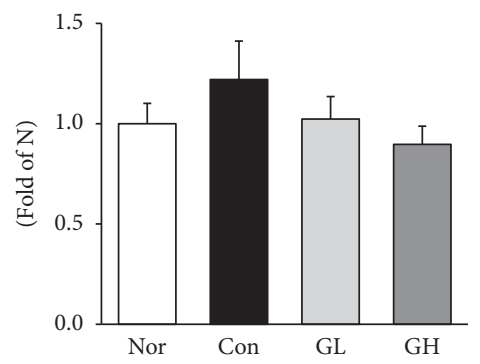

(a)

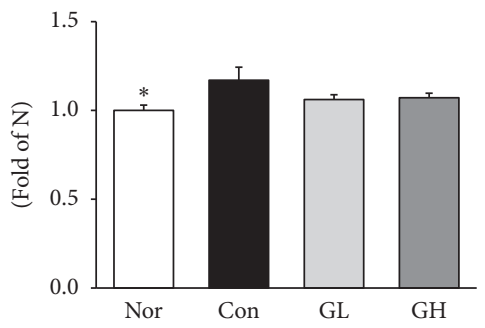

(d)

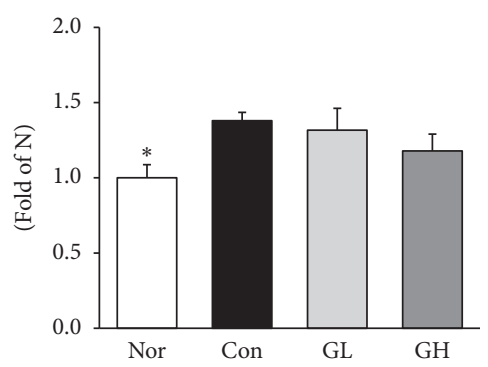

(b)

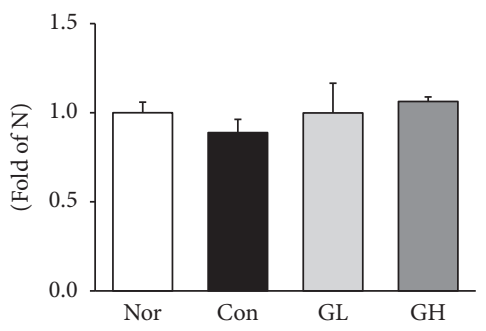

(e)

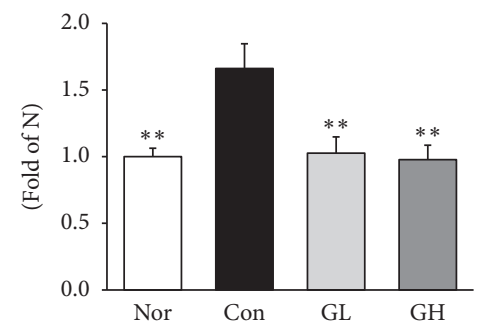

(c)

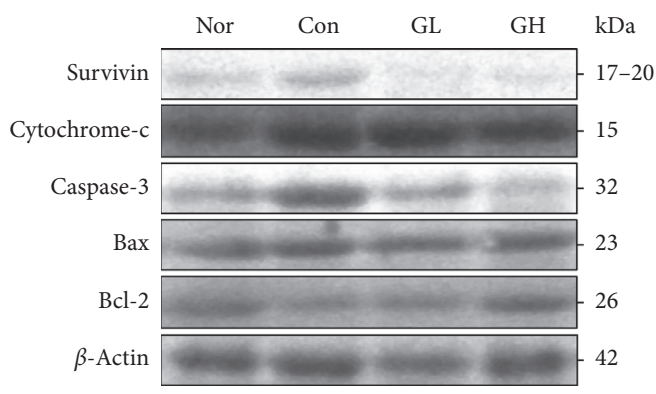

(f)

FIGURE 10: Western blot analysis of (a) survivin, (b) cytochrome c, (c) caspase-3, (d) Bax, and (e) Bcl-2 expressions. Nor: normal rats, Con: reflux esophagitis control rats, GL: GE $50 \mathrm{mg} / \mathrm{kg}$ treated reflux esophagitis rats, and GH: GE $100 \mathrm{mg} / \mathrm{kg}$ treated reflux esophagitis rats. (f) All data are expressed means \pm SEM, $(n=6)$ rats per group. Significance: ${ }^{*} p<0.05,{ }^{* *} p<0.01$ versus RE control rat values.

and caspase- 3 and the activation of $\mathrm{Bcl}-2$, an antiapoptotic protein $[50,51]$. The results showed that the GE treatment group tended to improve more than the control group in the acute model (Figure 10).

\section{Conclusions}

Our results show that the Gardeniae Fructus extract contains a considerable amount of geniposide of the flavonoid family and has an excellent antioxidant activity. Gardenia extract has been shown to be effective for acute reflux esophagitis by reducing oxidative stress in the esophagus and various inflammatory factors and protecting the esophageal mucosa.
Therefore, it is suggested that GE could be a potential remedy for the treatment of acute reflux esophagitis.

\section{Conflicts of Interest}

The authors declare that there are no conflicts of interest regarding the publication of this paper.

\section{Acknowledgments}

This study was supported by the National Research Foundation of Korea (NRF) and a grant from the Korean government (MSIP) (no. 2017R1A2B2006858). The current 
study was supported by the National Research Foundation of Korea (NRF) funded by Korean government (MSIP) (grant no. 2018R1A5A2025272).

\section{References}

[1] N. Vakil, S. V. van Zanten, P. Kahrilas, J. Dent, and R. Jones, "The montreal definition and classification of gastroesophageal reflux disease: a global evidence-based consensus," The American Journal of Gastroenterology, vol. 101, no. 8, pp. 1900-1920, 2006.

[2] L. Zhang, G. Liu, X. Han et al., "Inhibition of p38 MAPK activation attenuates esophageal mucosal damage in a chronic model of reflux esophagitis," Neurogastroenterology \& Motility, vol. 27, no. 11, pp. 1648-1656, 2015.

[3] S. Darvishmoghadam, M. J. Zahedi, M. M. Hayatbakhsh Abbasi, A. A. Haghdoost, M. Khalilyzade, and E. Karimi Goughari, "Review of clinical spectrum of gastroesophageal reflux disease in a general population; a study from south-east Iran," Middle East Journal of Digestive Diseases, vol. 8, no. 4, pp. 310-317, 2016.

[4] K. Takeuchi and K. Nagahama, "Animal model of acid-reflux esophagitis: pathogenic roles of acid/pepsin, prostaglandins, and amino acids," BioMed Research International, vol. 2014, Article ID 532594, 10 pages, 2014.

[5] R. C. Fitzgerald and G. Triadafilopoulos, "Recent developments in the molecular characterization of Barrett's esophagus," Digestive Diseases, vol. 16, no. 2, pp. 63-80, 1998.

[6] Y. J. Kim, E.-H. Kim, and K. B. Hahm, "Oxidative stress in inflammation-based gastrointestinal tract diseases: challenges and opportunities," Journal of Gastroenterology and Hepatology, vol. 27, no. 6, pp. 1004-1010, 2012.

[7] Y. Erbil, U. Türkoglu, U. Barbaros et al., "Oxidative damage in an experimentally induced gastric and gastroduodenal reflux model," Surgical Innovation, vol. 12, no. 3, pp. 219-225, 2005.

[8] M. W. Pawlik, S. Kwiecien, R. Pajdo et al., "Esophago protective activity of angiotensin-(1-7) in experimental model of acute reflux esophagitis. Evidence for the role of nitric oxide, sensory nerves, hypoxia-inducible factor-1alpha and proinflammatory cytokines," Journal of Physiology and Pharmacology, vol. 65, no. 6, pp. 809-822, 2014.

[9] J. S. Lee, T. Y. Oh, B. O. Ahn et al., "Involvement of oxidative stress in experimentally induced reflux esophagitis and Barrett's esophagus: clue for the chemoprevention of esophageal carcinoma by antioxidants," Mutation Research/Fundamental and Molecular Mechanisms of Mutagenesis, vol. 480-481, pp. 189-200, 2001.

[10] J. Li, F. Wang, Y. Xia et al., "Astaxanthin pretreatment attenuates hepatic ischemia reperfusion-induced apoptosis and autophagy via the ROS/MAPK pathway in mice," Marine Drugs, vol. 13, no. 6, pp. 3368-3387, 2015.

[11] R. Badillo and D. Francis, "Diagnosis and treatment of gastroesophageal reflux disease," World Journal of Gastrointestinal Pharmacology and Therapeutics, vol. 5, no. 4, pp. 105-112, 2016.

[12] Y. Wang, Y. Chen, L. Deng et al., "Systematic separation and purification of iridoid glycosides and crocetin derivatives from Gardenia jasminoides Ellis by high-speed counter-current chromatography," Phytochemical Analysis, vol. 26, no. 3, pp. 202-208, 2015.

[13] M. Nishizawa, R. Izuhara, K. Kaneko, Y. Koshihara, and Y. Fujimoto, "5-lipoxygenase inhibitors isolated from gardeniae fructus," Chemical \& Pharmaceutical Bulletin, vol. 36, no. 1, pp. 87-95, 1988.
[14] Y.-J. Hong and K.-S. Yang, "Anti-inflammatory activities of crocetin derivatives from processed Gardenia jasminoides," Archives of Pharmacal Research, vol. 36, no. 8, pp. 933-940, 2013.

[15] T. Hatano, R. Edamatsu, M. Hiramatsu et al., "Effects of the interaction of tannins with co-existing substances. VI. Effects of tannins and related polyphenols on superoxide anion radical, and on 1,1-diphenyl-2-picrylhydrazyl radical," Chemical \& Pharmaceutical Bulletin, vol. 37, no. 8, pp. 2016-2021, 1989.

[16] P. Kumkrai, O. Weeranantanapan, and N. Chudapongse, "Antioxidant, $\alpha$-glucosidase inhibitory activity and subchronic toxicity of Derris reticulata extract: its antidiabetic potential," BMC Complementary and Alternative Medicine, vol. 15, p. 35, 2015.

[17] R. Re, N. Pellegrini, A. Proteggente, A. Pannala, M. Yang, and C. Rice-Evans, "Antioxidant activity applying an improved ABTS radical cation decolorization assay," Free Radical Biology and Medicine, vol. 26, no. 9-10, pp. 1231-1237, 1999.

[18] N. Omura, H. Kashiwagi, G. Chen, Y. Suzuki, F. Yano, and T. Aoki, "Establishment of surgically induced chronic acid reflux esophagitis in rats," Scandinavian Journal of Gastroenterology, vol. 34, no. 10, pp. 948-953, 1999.

[19] S. F. Ali, C. P. LeBel, and S. C. Bondy, "Reactive oxygen species formation as a biomarker of methylmercury and trimethyltin neurotoxicity," Neurotoxicology, vol. 13, no. 3, pp. 637-648, 1992.

[20] S. Komatsu, "Extraction of nuclear protein," Methods in Molecular Biology, vol. 355, pp. 73-77, 2007.

[21] A. Altomare, M. P. Guarino, S. Cocca, S. Emerenziani, and M. Cicala, "Gastroesophageal reflux disease: update on inflammation and symptom perception," World Journal of Gastroenterology, vol. 19, no. 39, pp. 6523-6528, 2016.

[22] M. A. Jabri, H. Tounsi, K. Rtibi, L. Marzouki, M. Sakly, and H. Sebai, "Ameliorative and antioxidant effects of myrtle berry seed (Myrtus communis) extract during reflux-induced esophagitis in rats," Pharmaceutical Biology, vol. 25, no. 9, pp. 1575-1585, 2016.

[23] E. Hassall, "Decisions in diagnosing and managing chronic gastroesophageal reflux disease in children," The Journal of Pediatrics, vol. 146, no. 3, pp. S3-S12, 2005.

[24] B. I. Hirschowitz, "A critical analysis, with appropriate controls, of gastric acid and pepsin secretion in clinical esophagitis," Gastroenterology, vol. 101, no. 5, pp. 1149-1158, 1991.

[25] P. Singh, N. Singh, S. Sengupta, and G. Palit, "Ameliorative effects of Panax quinquefolium on experimentally induced reflux oesophagitis in rats," The Indian Journal of Medical Research, vol. 135, pp. 407-413, 2012.

[26] S. G. M. Meuwissen and E. C. Klinkenberg-Knol, "Treatment of reflux oesophagitis with H2-receptor antagonists," Scandinavian Journal of Gastroenterology, vol. 23, no. 146, pp. 201-213, 1988.

[27] T. Y. Oh, J. S. Lee, B. O. Ahn et al., "Oxidative stress is more important than acid in the pathogenesis of reflux oesophagitis in rats," Gut, vol. 49, no. 3, pp. 364-371, 2001.

[28] H.-J. Koo, K.-H. Lim, H.-J. Jung, and E.-H. Park, “Anti-inflammatory evaluation of gardenia extract, geniposide and genipin," Journal of Ethnopharmacology, vol. 103, no. 3, pp. 496-500, 2006.

[29] L. H. He, J. Li, Y. X. Deng, X. J. Zhang, R. Chen, and Y. Lv, "Comparative investigation on the pharmacokinetics of geniposide in type 2 diabetic and normal rats after oral 
administration of fructus gradeniae extract," Journal of Chromatography B, vol. 1033-1044, pp. 180-186, 2016.

[30] T.-R. Tsai, T.-Y. Tseng, C.-F. Chen, and T.-H. Tsai, "Identification and determination of geniposide contained in Gardenia jasminoides and in two preparations of mixed traditional Chinese medicines," Journal of Chromatography A, vol. 961, no. 1, pp. 83-88, 2002.

[31] B. Xu, Y.-1. Li, M. Xu et al., "Geniposide ameliorates TNBSinduced experimental colitis in rats via reducing inflammatory cytokine release and restoring impaired intestinal barrier function," Acta Pharmacologica Sinica, vol. 38, no. 5, pp. 688-698, 2017.

[32] D.-B. Lee, D.-H. Kim, and J.-Y. Je, “Antioxidant and cytoprotective effects of Lotus (Nelumbo nucifera) leaves phenolic fraction," Preventive Nutrition and Food Science, vol. 20, no. 1, pp. 22-28, 2015.

[33] N. Yoshida, "Oxidative stress in digestive disease guest editor: Yuji Naito inflammation and oxidative stress in gastroesophageal reflux disease," Journal of Clinical Biochemistry and Nutrition, vol. 40, no. 1, pp. 13-23, 2007.

[34] O. J. Kwon, M. Y. Kim, S. H. Shin et al., "Antioxidant and antiinflammatory effects of rhei rhizoma and coptidis rhizoma mixture on reflux esophagitis in rats," Evidence-Based Complementary and Alternative Medicine, vol. 2016, Article ID 2052180, 13 pages, 2016.

[35] A. Thomson, D. Hemphill, and K. N. Jeejeebhoy, "Oxidative stress and antioxidants in intestinal disease," Digestive Diseases, vol. 16, no. 3, pp. 152-158, 1998.

[36] E. Tutar, D. Ertem, G. Unluguzel et al., "Reactive oxygen species and chemokines: are they elevated in the esophageal mucosa of children with gastroesophageal reflux disease?," World Journal of Gastroenterology, vol. 14, no. 20, pp. 32183223, 2008.

[37] M. Garipardic, V. Bakan, M. Davutoğlu, H. Sayar, and E. B. Kurutaş, "Oxidative stress and protective effect of erythropoietin on methotrexate-induced esophageal damage," Journal of Pediatric Hematology/Oncology, vol. 32, no. 2, pp. 108-112, 2010.

[38] M. Ushio-Fukai and Y. Nakamura, "Reactive oxygen species and angiogenesis: NADPH oxidase as target for cancer therapy," Cancer Letters, vol. 266, no. 1, pp. 37-52, 2008.

[39] K. Bedard and K.-H. Krause, "The NOX family of ROSgenerating NADPH oxidases: physiology and pathophysiology," Physiological Reviews, vol. 87, no. 1, pp. 245-313, 2007.

[40] F. da Costa Gonçalves, M. Grings, N. S. Nunes et al., "Antioxidant properties of mesenchymal stem cells against oxidative stress in a murine model of colitis," Biotechnology Letters, vol. 39, no. 4, pp. 613-622, 2017.

[41] J. A. Johnson, D. A. Johnson, A. D. Kraft et al., "The Nrf2-ARE pathway: an indicator and modulator of oxidative stress in neurodegeneration," Annals of the New York Academy of Sciences, vol. 1147, no. 1, pp. 61-69, 2008.

[42] D. W. Hommes, M. P. Peppelenbosch, and S. J. van Deventer, "Mitogen activated protein (MAP) kinase signal transduction pathways and novel anti-inflammatory targets," Gut, vol. 52, no. 1, pp. 144-151, 2003.

[43] S. Y. Cho, S. J. Park, M. J. Kwon et al., "Quercetin suppresses proinflammatory cytokines production through MAP kinases and NF- $\kappa$ B pathway in lipopolysaccharide-stimulated macrophage," Molecular and Cellular Biochemistry, vol. 243, no. 12, pp. 153-160, 2003.

[44] J. M. Kyriakis and J. Avruch, "Mammalian mitogen-activated protein kinase signal transduction pathways activated by stress and inflammation," Physiological Reviews, vol. 81, no. 2, pp. 807-869, 2001.

[45] Y.-J. Feng, Y.-Y. Li, X.-H. Lin, K. Li, and M.-H. Cao, "Antiinflammatory effect of cannabinoid agonist WIN55, 212 on mouse experimental colitis is related to inhibition of p38MAPK," World Journal of Gastroenterology, vol. 22, no. 43, pp. 9515-9524, 2016.

[46] A. A. Tahir, N. F. Sani, N. A. Murad, S. Makpol, W. Z. Ngah, and Y. A. Yusof, "Combined ginger extract \& gelam honey modulate Ras/ERK and PI3K/AKT pathway genes in colon cancer HT29 cells," Nutrition Journal, vol. 14, no. 1, p. 31, 2015.

[47] M. S. Islam, T. Murata, M. Fujisawa et al., “Anti-inflammatory effects of phytosteryl ferulates in colitis induced by dextran sulphate sodium in mice," British Journal of Pharmacology, vol. 154, no. 4, pp. 812-824, 2009.

[48] W. Cao, L. Cheng, J. Behar, C. Fiocchi, P. Biancani, and K. M. Harnett, "Proinflammatory cytokines alter/reduce esophageal circular muscle contraction in experimental cat esophagitis," American Journal of Physiology-Gastrointestinal and Liver Physiology, vol. 287, no. 6, pp. G1131-G1139, 2004.

[49] W. L. Thompson and L. J. Van Eldik, "Inflammatory cytokines stimulate the chemokines CCL2/MCP-1 and CCL7/MCP-7 through $\mathrm{NF} \kappa \mathrm{B}$ and MAPK dependent pathways in rat astrocytes," Brain Research, vol. 1287, pp. 47-57, 2009.

[50] M. Redza-Dutordoir and D. A. Averill-Bates, "Activation of apoptosis signalling pathways by reactive oxygen species," Biochimica et Biophysica Acta (BBA)-Molecular Cell Research, vol. 1863, no. 12, pp. 2977-2992, 2016.

[51] J. Ju, G.-Y. Lee, Y.-S. Kim, H. K. Chang, M.-S. Do, and K.-Y. Park, "Bamboo salt suppresses colon carcinogenesis in C57BL/6 mice with chemically induced colitis," Journal of Medicinal Food, vol. 19, no. 11, pp. 1015-1022, 2016. 